\title{
Perception of Quality of Life at Patients after Surgery of Disc Herniation (Original research paper)
}

\section{Z. Slezakova (Zuzana Slezakova)1,2, G. Vorosova (Gabriela Vorosova)', K. Michalenkova (Kristina Michalenkova)²}

${ }^{1}$ Constantine the Philosopher University in Nitra,

Faculty of Social Sciences and Health Care, Department of Nursing, Nitra, Slovakia

2 St. Elizabeth College of Health and Social Work, Bratislava, Slovakia.

Depertment of Nursing

\section{E-mail address:}

zuzana.slezakova@health.gov.sk

\section{Reprint address:}

Zuzana Slezakova

Constantine the Philosopher University in Nitra

Faculty of Social Sciences and Health Care

Nitra, Slovakia

Suource: Clinical Social Work and Health Intervention

Pages: $43-48$
Volume: 8

Cited references: 19

Issue: 3

\section{Reviewers:}

Vladimir Krcmery

MIC Nairobi, Kenya

Gunther Dorfmeister

Vienna General Hospital, Vienna, AT

\section{Key words:}

D SF 36; nursing; Quality of Life, Hernation dicsu, Neurosurgery nursing.

\section{Publisher:}

International Society of Applied Preventive Medicine i-gap

CSWHI 2017; 8(3): 43 - 48; 10.22359/cswhi_8_3_08 @ 2017 Clinical Social Work and Health Intervention

\section{Abstract:}

Objective: Disc herniation affects a person in all aspects of life, physically, mentally and socially. In performing activities of daily living movement is limited; patients are often dependent on the help of others; the thinking and behavior of the patient are changing. At least one year 
after intervertebral discs surgery the overall assessment of the perception of quality of life should be change.

Design: We sought to ascertain the perception of quality in daily activities of life in areas of bio - psycho - social needs after disc herniation surgery.

Results: For diagnostic purposes evaluating the quality of life of patients after disc herniation surgery we used the questionnaire SF 36 (36-Item Heath Survey Short Form 36 Health Subject Questionnaire). Respondents were patients after disc herniation surgery $\mathrm{n}=86$ from neurosurgery clinics in Slovakia, $\mathrm{n}=86$.

Conclusions: We can state that for patients after disc herniation surgery quality of life only slightly improved: with restricted movement in the damaged area; problems with lifting heavy objects; persistent back pain. Our study of $n=86$ respondents showed that: In our study $n=86$ respondents showed that $84 \%$ of respondents stated that despite successful disc herniation surgery their normal daily activities are causing problems. $95 \%$ report that they still experience difficulties in carrying out daily activities and 33\% of patients still suffer from severe pain preventing them from doing normal activities. We found that $68 \%$ of respondents indicate that their normal daily activities cause problems because of their lingering emotional conditions, including anxiety, fear, depression and other conditions. Negative feelings such as anxiety, depression, sadness, exhaustion, fatigue was confirmed by $52 \%$ of patients. Although nearly half, $48 \%$ do experience a positive emotional condition. Conversations with respondents reveal that the social support and social contacts after spinal surgery are still rated relatively restrictive in intensity and frequency. The most effective social support respondents receive is from their families who often insure that rehabilitation and other services continue to be available.

\section{Introduction}

In the last two decades, the concept of the quality of life is thought to apply more to the individual, not so much on economic or social conditions. It has become the major research of the quality of life associated with healthy subjects (HRQOL $=$ Health-Related-Quality of Life) (Chisholm, Healey, Knapp 1997; Draper, J 2005). Health Related Quality of Life - HRQOL - thus the quality of life that is affected by health involves subjective perception of health for an individual, but also the perception of vital functions in health including physical and emotional spheres (Lebow et al. 2012).
WHO defines health as a state of complete physical, mental emotional and social well-being, not just the absence of disease. This definition implies that the measurement of health status and effects of the provision of healthcare must include not only the severity of the disease, but also an estimate of well-being. And, it is an estimate of well-being as it relates to an assessment of measuring actual quality of life. According to the WHO, this quality is considered to be a situation that is perceived individually by a certain culture; the system of value in relation to expectations; interests; evaluation 
criteria. Also, it is influenced by individual mental health; social relationships; physical health; degree of independence (Dzuka,2004). Gurkova, 2011 defines this is primarily a subjective feeling of well-being that include physical, mental, emotional, social and spiritual dimension:

Degeneration of intervertebral discs is associated with a sedentary work, total physical activity, turning, lifting, stretching, vibration while driving, improper posture and bad formula at work. So poor work factors increase the burden and stress that is placed on the back (Hakkinen et al., 2005 Kagaya et.al 2005 Heider et.al. 2007). Information on working conditions report that $30 \%$ of employed workers in Europe suffer from back pain which belongs at the top of the list of work-related disabilities. Other studies report increases in a variety of injuries including back injuries related to manual work and lifting heavy loads. Trouble-free life with no restrictions are causing sudden instant discomfort and the feeling of strong pain. It starts the cycle of neurology; neurosurgery; rehabilitation; examinations; difficulties in walking; dependency on others. Frustration occurs with chaos in the head, fear, anxiety, restrictions in daily activities of living.

Design: For diagnosis mapping of quality of life after disc herniation surgery we used questionnaire SF 36 - Short Form 36 Health Subject Questionnaire (SF-36) by Ware and Sherbourne (1992).

Results: In research participation $\mathrm{n}=86$ respondents (38\% women and $62 \%$ men). The age limit of the respondents ranged from 18 to 61 and above. The largest sample consisted of respondents aged 31-50 years which was $64 \%$. The research sample consisted of patients at least one year after surgery on intervertebral discs in the neurosurgery clinic of a Hospital in Slovakia.

\section{Methods}

For diagnosis mapping quality of life after surgery of disc herniation we used questionnaire SF 36 (Short Form 36 Health Subject Questionnaire) questionnaire Short Form 36 (SF-36) Ware and Sherbourne (1992. The questionnaire contains 36 questions focused on the last four weeks, divided into 8 dimensions. For each dimension there can be a $\mathrm{T}$ - score between $0-100$, which expresses the degree of health and the affect on normal patient activities, where zero corresponds to a lower health status and 100 to the best health status. Dimensions are: objective physical functions (PF), social functions (SF), limitations in physical roles (RP), the limitations in emotional roles (RE), managing emotions and subjective well-being (MH), vitality (VT), pain (BP), subjective assessment of the health $(\mathrm{GH})$, perceived health change $(\mathrm{CH})$. In addition to basic dimensions questionnaire allows the evaluation of summary dimensions: perceived physical health (SPH), perceived mental health $(\mathrm{SMH})$, perceived health status (PHS). We used the Chi- square test for the comparison of qualitative variables finding the frequency of occurrence.

\section{Results}

Based onstatisticalanalysis, we present the data obtained in the individual components of the SF 36, comparing gender to physical activity, mental, emotional and social activity. The achieved result $\mathrm{p}=8.271 * 10-5$ is significantly smaller than the level of 0.05 . In general, this means the health of patients negatively affects normal daily activities. When compared to women, even though not an equal number of respondents women to men, we found that men suffer more with physical limitations than do women.

The achieved level of statistical significance is less than 0.05 . The results show that 
in the last four weeks men had at least one of the named problems (e.g. reducing the time to work or take other action; reducing certain types of tasks or activities; expending more effort to carry out the work or activities) compared with women who have these common activities better managed.

On the basis of statistical indicators, we concluded that to physically improve the quality of life for women after disc herniation surgery, they must be able to perform activities of daily living better than men after disc herniation surgery. On the basis of statistical indicators, we concluded that after disc herniation surgery women emotionally feel less nervousness, sadness or tension than men. After disc herniation surgery, women did not have to restrict meetings with friends or have restrictions on the conduct of social activities. The achieved level of statistical significance is greater than 0.05 . This means that the men greatly hinder their emotional health problems in social life.

\section{Discussion}

In there research, Laxton W. and G. Perrin R. (2003) and D. Heider (2007) reported that pain and mobility problems associated with disease reduces abilities to be productive at home and at work. Generally, during the day, the patient's condition negatively affects normal daily activities. We agree with these authors. Results obtained show that due to their post-surgery mode, the majority of patients after surgery depend respectively on others as well as family members. They need help whether dressing, bathing and other daily living activities that have managed in the full health without help. Pain in even moderate activities limited up to $71 \%$ of patients; $50 \%$ reaching; 64\% bathing and dressing; walking up the stairs make problems for the majority of respondents.
In our survey, we found that most patients report needing extra time to carry out normal activities and expending more effort and energy to carry out normal activities. In their studies, several authors (Hakkinen et al. 2005 Schneider, et.al. 2007), as we also have identified. report persistence of pain even 12 months after surgery. When comparing between men and women, we found the perception of quality of life for women has improved after disc herniation surgery and they are physically able to perform activities of daily living better than men after similar disc herniation surgery.

Evaluating the results of the psychological field four weeks after surgery $52 \%$ of respondents complained of fatigue; $40 \%$ of depression and sadness; $58 \%$ at patients experienced nervousness. Compared with research, authored by Lebow (2012), which compared negative emotional states after surgery, he found that with decreasing pain intensity decreased feelings of anxiety and depression. Rehabilitation can fully improve mental status with the disappearance of pain. Also, in the research, conducted by Heider (2007) it concluded that in most of the patients their emotional feelings are related to the intensity of their pain. The researchers found an increased incidence of depression, anxiety, dissatisfaction with financial situation, reflected in family relationships. Laxton and Perrin (2003) found in their research that patients suffering from anxiety have a reduced incentive to rehabilitation and post-surgery results are worse. On the other hand, the psychological aspect is closely linked with the social and physical aspects, so if patients feel less pain and cope better with every day care for themselves their social viewpoint will not be limiting; their everyday mental attitude will offer a better way to get rid of unpleasant emotional feelings. Our research tells us that the pain in men after surgery prevented quite 
a lot of routine work compared to women. In the last four weeks, in comparison with men, women did not feel their emotional problems in normal daily activities; as well, women did not feel negative emotional expressions related to anxiety, depression, sadness, exhaustion and fatigue as much as for men. After disc herniation surgery, women emotionally feel less nervousness, sadness and tension than men.

From the perspective of the respondents after spine surgery, the intensity and frequency social support and social contacts are rated as relatively restrictive. The biggest social support respondents receive is from their family and this is often also backed by rehabilitation and other available services. In Germany, compared with the research sample (Heider, 2007), which divided the patients into a groups of singles and those in partnership, they found that in social relations, singles need increased support as they have more difficulties to deal with diseases compared with patients who have the support of people close by. Other research (Laxon and Perrin, 2003) showed that with post-surgery complications after disc herniation spinal surgery, there was a lack of social support from family relationships due to the inconvenience as well as increased nervousness and than in patients who didn't have complications. They predicted that with increased of social support to them it will facilitate patient's quality of life after of spinal surgery. To some extent, this was also confirmed, especially among people who had their loved one close. In our survey, despite health and emotional problems after disc herniation surgery, women manage their recovery better nor does it prevent them building social contacts and social life more easily than men. We can say that the quality of life for patients after disc herniation surgery only slightly improved and that restricted movement in the damaged area, problems with lifting, and back pain remain. This is also in accordance with previous research presented in patients of both genders. Therefore, it would be appropriate to focus future research on the possibilities of preventive measures in relation to disc herniation.

\section{Reference}

1. BURKS JS, JOHNSON KP (2000) Multiple sclerosis. New York: Demos 2000: 377 s.

2. DZUKA J (2004) Psychologic Dimensions of quality of life. Presov: University of Presov, 2004. ISBN 80-8068-282-8.

3. DRAGOMIRECKA E, BARTONOVA J (2006) Whoqol-Bref, Whoqol-100. Health Organization Quality of Life Assessment. 1. pub. Praha: 2006

4. LAXTON W, PERRIN R G (2003) The relations between social support, life stress, and quality of Life following spinal decompression surgery. [online] 2003. [cit. 20. 2. 2015]. http://www.nature.com/sc/journal/ v41/n10/full/3101432a.html.

5. LEBOW R et al (2012) Microdiscectomy improves pain-associated depression, somatic anxiety, and mental well-being in patients with herniated lumbar disc. Neurosurgery 70.2 (2012): 306-311.

6. HEIDER D et al (2007) Health-related quality of life in patients after lumbar disc surgery: a longitudinal observational study. Quality of Life Research 16.9 (2007): 14531460.

7. KAGAYAA, HITOSHI P, et al (2005) Quality of life assessment before and after lumbar disc surgery. Journal of Orthopaedic Science 10.5 (2005): 486-489.

8. HAKKINEN A, et al (2005) Health related quality of life after lumbar disc surgery: a prospective study of 145 patients. Disability and rehabilitation 27.3 (2005): 94-100.

9. CHISHOLM D (1), HEALEY A, KNAPP P (1997) QALYs and mental health care. Soc. Psychiatry Psychiatr Epidemiol. 1997 Feb;32(2):68-75. 
10. FAYERS P M, MACHIN D (2000) Quality of Life: Assessment, Analysis, Interpretation. First edition. Chichester: John Wiley and Sons Ltd., 2000, $395 \mathrm{~s}$.

11. GURKOVA E (2011) Assessing the quality of life. 1. vyd. Praha: Grada publishing, 2011. 224s. ISBN 978-80-247-3625-9.

12. KUCERA P (2006) Pain and neuropathy. In: Via practica. ISSN 1336 - 4790. roč. III., 2006. č. 12, s 562 - 566.

13. KING CYNTHIA R, HINDS PAMELA S (2011) Quality of life: From nursing and patient perspectives. Jones \& Bartlett Publishers, 2011.

14. DRAPER P (2005) Nursing perspectives on quality of life. Routledge, 2005. ISBN 0-203-99276-8 Master e-book ISBN

15. PAYNE J et al (2005) Quality of life and health. Praha: Triton, 2005. ISBN 80-7254657-0
16. SCHNEIDER C, KRAYENBUHL N, LANDOLT H (2007) Conservative treatment of lumbar disc disease: patient's quality of life compared to an unexposed cohort. Acta neurochirurgica 149.8 (2007): 783791.

17. THE WORLD HEALTH ORGANIZATION (1999) Annotated Bibliography of the WHO Quality of Life Assessment Instrument - WHOQOL. [online]. [cit. 2015-12-04]. http://depts.washington.edu/seaqol/docs/ WHOQOL_Bibliography.pdf

18. TYLL T, DOSTALOV V, NETUKA D et al (2014) Neuroanestezie Praha 4: Mlada fronta, 2014. 310s. ISBN 978-80-204-3148-6.

19. ESCH S, FRICCHIONE G, HERBERT B (2002) The role of stress in neurodegenerative diseases and mental disorders. Neuroendocrinology letters. 2002; 23:199-208. ISSSN 0172-780X. 